\title{
New trends in nuclear data research for medical radionuclide production
}

\author{
By S. M. Qaim* \\ Institut für Neurowissenschaften und Medizin, INM-5: Nuklearchemie, Forschungszentrum Jülich GmbH, D-52425 Jülich, Germany
}

(Received January 25, 2013; accepted in revised form March 21, 2013)

(Published online July 15, 2013)

\begin{abstract}
Medical radionuclide / Optimisation of production route / Nuclear reaction cross section / Standardisation of data / Alternative routes for production of ${ }^{99 \mathrm{~m}} \mathrm{Tc}$ and ${ }^{68} \mathrm{Ga} /$ Non-standard positron emitter / Novel therapeutic radionuclide
\end{abstract}

\begin{abstract}
Summary. Nuclear reaction cross section data are of great significance in optimisation of production routes of radionuclides. This article deals with some newer aspects of data research related to production of both standard and novel radionuclides. The recent work to standardise the known data is discussed and new measurements with regard to further optimisation of production routes of some commonly used radionuclides are mentioned. Attempts to increase the specific activity of some reactor-produced radionuclides through the use of charged-particle induced reactions are outlined. The jeopardy in the supply of ${ }^{99 \mathrm{~m}} \mathrm{Tc}$ via a fission-produced ${ }^{99} \mathrm{Mo} /{ }^{99 \mathrm{~m}} \mathrm{Tc}$ generator is considered and its possible direct production at a cyclotron is briefly discussed. Regarding the novel radionuclides, development work is presently focussed on non-standard positron emitters for diagnosis and on low-range highly ionising radiation emitters for internal radiotherapy. Recent nuclear reaction cross section measurements related to the production of the two types of radionuclides are briefly reviewed and some anticipated trends in nuclear data research are considered.
\end{abstract}

\section{Introduction}

Radionuclides find application in both medical diagnosis and internal radiotherapy [cf. 1]. A suitable radionuclide in a proper chemical form is generally administered into the human body to allow diagnostic studies or to induce therapeutic effect. The underlying principle of in vivo medical diagnosis is that the radiation dose to the patient is minimum. This is achieved through imaging of the human organ from outside of the body using short-lived radionuclides, emitting predominantly a gamma ray in the energy range of 70-250 keV or a positron. The low-energy gamma ray facilitates single photon emission computed tomography (SPECT), and the positron emitter allows positron emission tomography (PET). In contrast to diagnosis, internal radio-

\footnotetext{
*E-mail: s.m.qaim@fz-juelich.de.
}

therapy stipulates that a certain radiation dose is specifically deposited in the malignant tissue. This is brought about through the use of radionuclides emitting corpuscular radiation, i.e., alpha- or beta-particles, or Auger and conversion electrons, in combination with a targeted-compound labelled with the radionuclide. In all those applications a knowledge of nuclear data plays an important role. Whereas the radioactive decay data are of importance in the choice of a radionuclide for a particular diagnostic or therapeutic application, the nuclear reaction cross section data are of great significance in optimisation of the production route of a desired radionuclide (for earlier reviews [cf. 2-7]).

The production of radionuclides is carried out using nuclear reactors as well as cyclotrons. In reactor production generally $(n, \gamma)$ and $(n, f)$ processes are utilized. Occasionally $(n, p)$ and double neutron capture reactions are also used. The radioactive products are often neutron excess radionuclides. They mostly decay by $\beta^{-}$emission and are therefore especially suited for internal radiotherapy. The cyclotron produced radionuclides, on the other hand, are mainly neutron deficient and decay by electron capture (EC) or $\beta^{+}$emission. They are therefore ideally suited for diagnostic studies. The positron emitters are almost exclusively produced using charged-particle accelerators. For production of some radionuclides both nuclear reactors and cyclotrons (accelerators) are extensively used.

This article deals with nuclear reaction cross section data for production of medical radionuclides, with emphasis on some newer aspects. The progress made within the last decade is briefly mentioned. It is not the aim of this short review to enlist all recent publications in the field; instead some typical examples for each aspect are given. Some anticipated trends in nuclear data research are outlined.

\section{Standardisation of data}

A vast amount of experimental data is available in the EXFOR file, coordinated by the IAEA. In the case of neutron-induced reactions, the data have been extensively evaluated and standardised, mainly in the context of energy research, and the recommended data are available in several data files ( $c f$. ENDF/B-VII). Those data are useful also for radionuclide production in reactors. Despite this progress, 
there was still need of evaluation and standardisation of data for many of the reactor-produced therapeutic radionuclides.

Also for charged-particle induced reactions used in radionuclide production, generally a large number of measurements were available in the literature. However, no serious evaluation effort was reported. The IAEA embarked on this mission about 16 years ago and organised two successive co-ordinated research programmes (CRPs) in which about a dozen laboratories participated. Since no evaluation methodology existed at that time for charged-particle induced reactions, the initial work was rather empirical. It involved normalisation of the data (in case of outdated decay intensities and monitor cross sections), simple nuclear model calculations and statistical fitting of the data. However, in later years strong application of nuclear models could be built in. The evaluated and recommended data for the major diagnostic radionuclides are now available in [8] and those for the therapeutic radionuclides in [9]. The latter includes both reactor and cyclotron produced therapeutic radionuclides. The standardised data should now allow a proper selection of the projectile energy range in a target to ensure high radionuclidic purity of the desired product. In addition, theoretical yields of the desired radionuclide and the accompanying radioactive impurities can be accurately calculated from the evaluated excitation functions. A few groups are now also individually engaged in this type of studies [cf. 10,11]. Further work on the validation of evaluated data as well as on the evaluation of data for other emerging radionuclides is necessary.

\section{Optimisation studies relevant to production routes of some standard radionuclides}

During the standardisation work it was found that the production data of some commonly used radionuclides were rather discrepant or lacked the required accuracy, calling upon more precise measurements. In a few other cases it was realized that the data for the formation of some impurities needed more attention. A brief account of some newer measurements is given below.

With regard to the standard PET radionuclides, some measurements were done relevant to the production of ${ }^{11} \mathrm{C}$ $\left(T_{1 / 2}=20 \mathrm{~min}\right)$ via the ${ }^{14} \mathrm{~N}(p, \alpha){ }^{11} \mathrm{C}$ reaction, where the formation of the undesired radionuclides ${ }^{14} \mathrm{O}\left(T_{1 / 2}=70 \mathrm{~s}\right)$ and ${ }^{13} \mathrm{~N}\left(T_{1 / 2}=10 \mathrm{~min}\right)$ occurs via the reactions ${ }^{14} \mathrm{~N}(p, n){ }^{14} \mathrm{O}$ and ${ }^{14} \mathrm{~N}(p, p n){ }^{13} \mathrm{~N}$, respectively [12]. The results are shown in Fig. 1. Those data make it possible to calculate the two radioactive impurities formed during the production of ${ }^{11} \mathrm{C}$. For the optimum proton energy range within the nitrogen gas target $\left(E_{\mathrm{p}}=13 \rightarrow 4 \mathrm{MeV}\right)$ it is estimated that the ${ }^{11} \mathrm{C}$ formed will contain about $20 \%{ }^{14} \mathrm{O}$ and $5 \%{ }^{13} \mathrm{~N}$ at the end of irradiation. Similarly for the production of ${ }^{18} \mathrm{~F}\left(T_{1 / 2}=110 \mathrm{~min}\right)$ via the ${ }^{18} \mathrm{O}(p, n){ }^{18} \mathrm{~F}$ reaction, the cross section database was extended up to $30 \mathrm{MeV}$ [13], so that large scale production of this radionuclide using medium-sized cyclotrons could be carried out. Furthermore, measurements on the formation of some short-lived positron emitters were extended up to proton energies of about $200 \mathrm{MeV}$ [14]. However, the highenergy data are of more relevance to proton therapy than to radionuclide production.

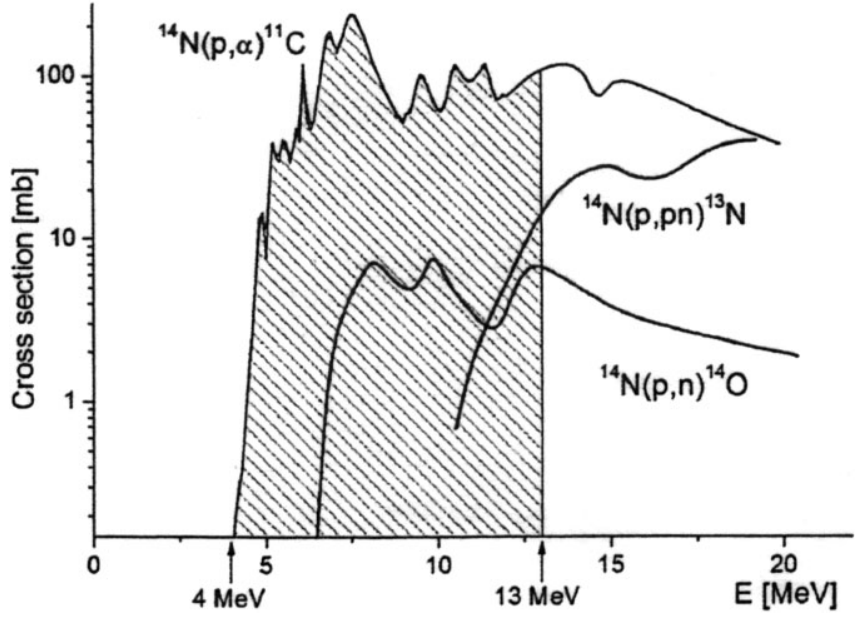

Fig. 1. Excitation functions of proton induced nuclear reactions on ${ }^{14} \mathrm{~N}$ (after Ref. [12]).

Some discrepancies existed in the data for the production of the radionuclides ${ }^{68} \mathrm{Ge}\left(T_{1 / 2}=270 \mathrm{~d}\right)$ and ${ }^{82} \mathrm{Sr}$ $\left(T_{1 / 2}=25.5 \mathrm{~d}\right)$ which are used as parents of the generatorproduced commonly used $\beta^{+}$emitting radionuclides ${ }^{68} \mathrm{Ga}$ $\left(T_{1 / 2}=1.13 \mathrm{~h}\right)$ and ${ }^{82} \mathrm{Rb}\left(T_{1 / 2}=1.3 \mathrm{~min}\right)$, respectively. They are employed especially at PET centres without a cyclotron. A recent measurement on the ${ }^{\text {nat }} \mathrm{Rb}(p, x)^{82} \mathrm{Sr}$ reaction [15] solved the discrepancy about the production data of ${ }^{82} \mathrm{Sr}$; the measured and calculated thick target yields of ${ }^{82} \mathrm{Sr}$ over different energy ranges were found to be in good agreement [15]. Regarding the production of ${ }^{68} \mathrm{Ge}$ via the ${ }^{\text {nat }} \mathrm{Ga}(p, x)$-process, a very recent measurement of the excitation function has strengthened the database [16].

As far as the SPECT radionuclides are concerned, the production data for all five commonly used radionuclides, viz. ${ }^{67} \mathrm{Ga}\left(T_{1 / 2}=3.26 \mathrm{~d}\right),{ }^{99 \mathrm{~m}} \mathrm{Tc}\left(T_{1 / 2}=6.0 \mathrm{~h}\right),{ }^{111} \mathrm{In}$ $\left(T_{1 / 2}=2.8 \mathrm{~d}\right),{ }^{123} \mathrm{I}\left(T_{1 / 2}=13.2 \mathrm{~h}\right)$ and ${ }^{201} \mathrm{Tl}\left(T_{1 / 2}=73.0 \mathrm{~h}\right)$, are generally well known. Whereas the radionuclide ${ }^{99 \mathrm{~m}} \mathrm{Tc}$ is mostly obtained via a fission-produced ${ }^{99} \mathrm{Mo} /{ }^{99 \mathrm{~m}} \mathrm{Tc}$ generator system, the other four radionuclides are produced using a medium-sized cyclotron. Only in a few special cases some data problems existed. The production of ${ }^{123} \mathrm{I}$ via the ${ }^{124} \mathrm{Xe}(p, x)^{123} \mathrm{I}$ process, for example, proceeds through two routes, namely $\left.{ }^{124} \mathrm{Xe}(p, 2 n)\right)^{123} \mathrm{Cs} \rightarrow{ }^{123} \mathrm{Xe} \rightarrow{ }^{123} \mathrm{I}$ and ${ }^{124} \mathrm{Xe}(p, p n){ }^{123} \mathrm{Xe} \rightarrow{ }^{123} \mathrm{I}$. Whereas the data for the first route are well established, there exists some discrepancy in the case of direct formation of ${ }^{123} \mathrm{Xe}$. The effect of the discrepancy on the routine production of ${ }^{123} \mathrm{I}$ is, however, of little significance. The level of the only radionuclidic impurity ${ }^{121} \mathrm{I}\left(T_{1 / 2}=2.1 \mathrm{~h}\right)$ is negligibly small. However, it has been recently shown [17] that if the incident proton energy exceeds $30 \mathrm{MeV}$, the cross section of the process ${ }^{124} \mathrm{Xe}(p, x)^{121} \mathrm{I}$ becomes appreciable. The latter decays to long-lived ${ }^{121} \mathrm{Te}\left(T_{1 / 2}=154 \mathrm{~d}\right)$ which is a disadvantage. An energy control of the beam incident on the target is therefore mandatory. It has been suggested to limit the beam energy to $35 \mathrm{MeV}$ and reduce the ${ }^{121} \mathrm{Te}$ content by adapting cooling times [17].

For calibration of SPECT machines the long-lived radionuclide ${ }^{57} \mathrm{Co}\left(T_{1 / 2}=271 \mathrm{~d}\right)$ is commonly used. Some new cross section measurements relevant to its production in nocarrier-added form [18] have strengthened the database. 
The status of data for the production of common therapeutic radionuclides is fairly good [ $c f .9]$, and only a few new measurements have been performed in recent years. For example, with regard to the production of ${ }^{32} \mathrm{P}\left(T_{1 / 2}=14.3 \mathrm{~d}\right)$, ${ }^{67} \mathrm{Cu}\left(T_{1 / 2}=2.58 \mathrm{~d}\right)$ and ${ }^{89} \mathrm{Sr}\left(T_{1 / 2}=50.5 \mathrm{~d}\right)$ via the nuclear reactions $\left.{ }^{32} \mathrm{~S}(n, p)\right)^{32} \mathrm{P},{ }^{67} \mathrm{Zn}(n, p){ }^{67} \mathrm{Cu}$ and ${ }^{89} \mathrm{Y}(n, p){ }^{89} \mathrm{Sr}$, respectively, integral cross section measurements were performed $[19,20]$ using a $14 \mathrm{MeV} d(\mathrm{Be})$ neutron source. A discussion of the results led to the conclusion that higher yields of those radionuclides would be obtained using a spallation neutron source than the present day fission reactors. Cross section measurements on the production of a few therapeutic radionuclides in a nuclear reactor have also been reported [cf. 21, 22].

\section{Attempts to improve the specific activity of some reactor-produced therapeutic radionuclides}

Many of the therapeutic radionuclides are produced in a nuclear reactor, generally via the $(n, \gamma)$ process, and the specific activity (i.e. the radioactivity/unit mass of all isotopes of the element present) achieved is rather low. Some of them can be obtained in no-carrier-added form through precursor decay, generator formation, ( $n$,charged particle) nuclear reaction or fission process. There are, however, several important or potentially important therapeutic radionuclides like ${ }^{103} \mathrm{Pd}\left(T_{1 / 2}=17.0 \mathrm{~d}\right),{ }^{153} \mathrm{Sm}\left(T_{1 / 2}=1.9 \mathrm{~d}\right),{ }^{169} \mathrm{Er}$ $\left(T_{1 / 2}=9.4 \mathrm{~d}\right),{ }^{169} \mathrm{Yb}\left(T_{1 / 2}=32.0 \mathrm{~d}\right),{ }^{186} \operatorname{Re}\left(T_{1 / 2}=3.7 \mathrm{~d}\right)$, ${ }^{192} \operatorname{Ir}\left(T_{1 / 2}=73.8 \mathrm{~d}\right)$, etc. where all those methodologies do not function. Furthermore, the production of ${ }^{64} \mathrm{Cu}\left(T_{1 / 2}=\right.$ $12.7 \mathrm{~h})$ and ${ }^{67} \mathrm{Cu}\left(T_{1 / 2}=2.6 \mathrm{~d}\right)$ via the ${ }^{64} \mathrm{Zn}(n, p){ }^{64} \mathrm{Cu}$ and ${ }^{67} \mathrm{Zn}(n, p){ }^{67} \mathrm{Cu}$ processes does not provide products of sufficient purity. In recent years, therefore, charged-particle induced reactions have been extensively investigated, especially at Brussels, Debrecen and Jülich, to explore the production of those radionuclides in no-carrier-added form. In particular for ${ }^{64} \mathrm{Cu}$ and ${ }^{103} \mathrm{Pd}$ a large number of reactions have been studied [for recent reviews $c f .9,11,23$ ], out of which the ${ }^{64} \mathrm{Ni}(p, n){ }^{64} \mathrm{Cu}$ and ${ }^{103} \mathrm{Rh}(p, n){ }^{103} \mathrm{Pd}$ processes have been successfully developed for large scale production of the two radionuclides. For ${ }^{67} \mathrm{Cu}$ and ${ }^{186} \mathrm{Re}$, the methods are still in development (see below). Regarding the other above mentioned radionuclides, the investigated processes [cf. 24-30] are not economical because the resulting yields are too low. The radionuclide ${ }^{192} \mathrm{Ir}$ is used in brachytherapy and the radionuclide ${ }^{169} \mathrm{Yb}$ is a potential candidate for brachytherapy. For that purpose the reactor production is adequate. Regarding ${ }^{169} \mathrm{Er}$, the real application needs to be demonstrated. The main problem regarding the specific activity is thus presently with ${ }^{153} \mathrm{Sm}$ which is now often used in internal radiotherapy. For this radionuclide, the use of the ${ }^{150} \mathrm{Nd}(\alpha, n)$ reaction on a highly enriched target appears to be of some promise. The measured excitation function [31] is shown in Fig. 2. The yield of ${ }^{153} \mathrm{Sm}$ over the energy range $E_{\alpha}=25 \rightarrow 15 \mathrm{MeV}$ amounts to $2.2 \mathrm{MBq} / \mu \mathrm{Ah}$, with no significant impurity. Thus a high specific-activity and high radionuclidic-purity product could be obtained in a quantity sufficient for medical application, but the cost would be rather high.

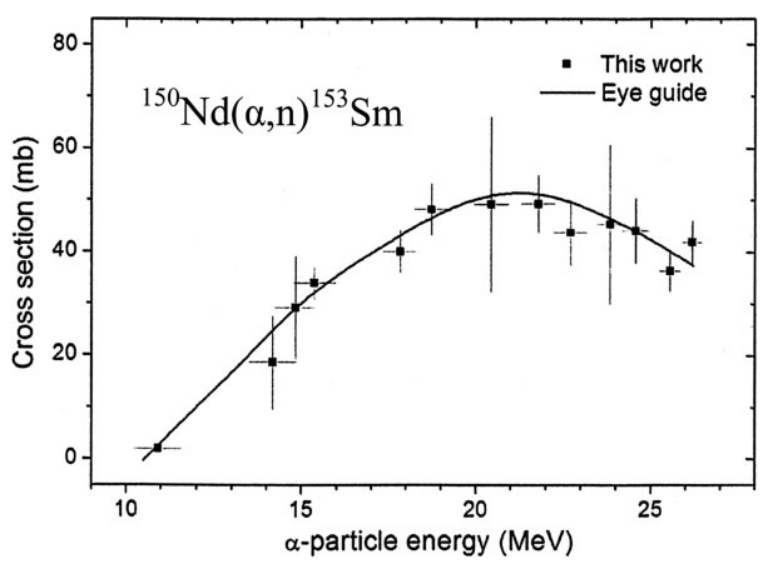

Fig. 2. Excitation function of the ${ }^{150} \mathrm{Nd}(\alpha, n){ }^{153} \mathrm{Sm}$ reaction (after Ref. [31]).

\section{Security of supply of ${ }^{99 \mathrm{~m}} \mathrm{Tc}$ and ${ }^{68} \mathrm{Ga}$ : search for alternative production routes}

The generator-produced radionuclide ${ }^{99 \mathrm{~m}} \mathrm{Tc}\left(T_{1 / 2}=6.0 \mathrm{~h}\right)$ is the most commonly used agent in diagnostic studies. Its supply is rather jeopardized due to increasing uncertainty in availability of the fission-produced ${ }^{99} \mathrm{Mo}\left(T_{1 / 2}=66.0 \mathrm{~h}\right)$ for preparation of generators (ageing reactors, problem with using highly-enriched ${ }^{235} \mathrm{U}$ as target material, etc.). An intense search for alternative routes of production of ${ }^{99} \mathrm{Mo}$ and ${ }^{99 \mathrm{~m}} \mathrm{Tc}$ has therefore been going on for more than a decade. Several routes have been suggested and their cross sections have been measured (for a recent review [cf. 7]). Out of all those processes the direct production of ${ }^{99 \mathrm{~m}} \mathrm{Tc}$ via the ${ }^{100} \operatorname{Mo}(p, 2 n)$-reaction appears to be more promising. Several measurements have been reported in recent years [32-36] and the data show large scatter, especially over the energy range of $10-20 \mathrm{MeV}$. Nuclear model calculations show [37] that the more recent data [33-36] are consistent. An evaluation has produced a recommended set of cross sections [37], which should allow calculation of the yield with enhanced confidence. Over the suitable energy range of $E_{\mathrm{p}}=22 \rightarrow 10 \mathrm{MeV}$, the calculated yield of ${ }^{99 \mathrm{~m}} \mathrm{Tc}$ amounts to $700 \mathrm{MBq} / \mu \mathrm{A} h$. Technical efforts to produce ${ }^{99 \mathrm{~m}} \mathrm{Tc}$ via this route are now underway. The levels of long-lived impurities and their implications on the pharmaceutical quality of ${ }^{99 \mathrm{~m}} \mathrm{Tc}$, however, need to be extensively investigated.

Besides ${ }^{99 \mathrm{~m}} \mathrm{Tc}$, the availability of the radionuclide ${ }^{68} \mathrm{Ga}$ $\left(T_{1 / 2}=1.1 \mathrm{~h}\right)$ is also causing some concern. It is a $\beta^{+}$emitting generator-produced radionuclide and is finding increasing application in PET studies, especially in developing countries. The parent radionuclide ${ }^{68} \mathrm{Ge}\left(T_{1 / 2}=270 \mathrm{~d}\right)$ is a relatively long-lived cyclotron product and there could be jeopardy about its supply. Some studies on the direct production of ${ }^{68} \mathrm{Ga}$ via the ${ }^{68} \mathrm{Zn}(p, n){ }^{68} \mathrm{Ga}$ and ${ }^{65} \mathrm{Cu}(\alpha, n){ }^{68} \mathrm{Ga}$ reactions have been reported [ $c f .38]$. The prospects of direct production of ${ }^{68} \mathrm{Ga}$ are good but, due to low yield, the adopted procedure will remain limited to in-house use.

\section{Research-oriented radionuclides}

Constant research work is going on with the aim to develop novel radionuclides for newer applications in medicine, both 
diagnostic and therapeutic. Many of the nuclear data studies are, however, only of academic interest, with little chances of real application. The more important developments in the two directions are treated below separately.

\subsection{Non-standard positron emitters}

In view of the enhancing significance of PET, considerable efforts have been devoted over the last 30 years towards development of a large number of non-standard, i.e. non-conventional positron emitters. There have been two motivations: a) study of slow metabolic processes; b) quantification of imaging and dosimetry. Two detailed review articles $[6,39]$ have recently been published on the development of about 25 novel positron emitters. In this article, therefore, only some salient features related to nuclear data work are discussed.

Out of all non-standard positron emitters recently developed, three radionuclides, viz. ${ }^{64} \mathrm{Cu}\left(T_{1 / 2}=12.7 \mathrm{~h}\right),{ }^{124} \mathrm{I}$ $\left(T_{1 / 2}=4.2 \mathrm{~d}\right)$ and ${ }^{86} \mathrm{Y}\left(T_{1 / 2}=16.0 \mathrm{~h}\right)$, are finding worldwide application. They are opening new perspectives in radioimmunotherapy and radiation dosimetry. The commonly used production method in each case is the low-energy $(p, n)$ reaction on the respective highly-enriched target nucleus. The basic data in all three cases were measured at the Forschungszentrum Jülich [40-42]. Although extensive development work related to targetry and chemical separation of those radionuclides has been done in many laboratories (for review cf. [6,7]), only one new data measurement has been reported for the ${ }^{64} \mathrm{Ni}(p, n){ }^{64} \mathrm{Cu}$ reaction [43]. On the other hand, for the three radionuclides under discussion, intermediate energy-reactions have been investigated by several groups $[c f .10,41,44-54]$ and data evaluation has also been performed $[c f .9,10,23,55,56]$. Nonetheless, it is concluded that for each of those three radionuclides the respective $(p, n)$ reaction gives the purest product, though the yield is not very high.

Besides the above mentioned three established nonstandard positron emitters, there is great potential interest in other positron emitters as well, e.g. ${ }^{72} \mathrm{As}\left(T_{1 / 2}=26.0 \mathrm{~h}\right)$,

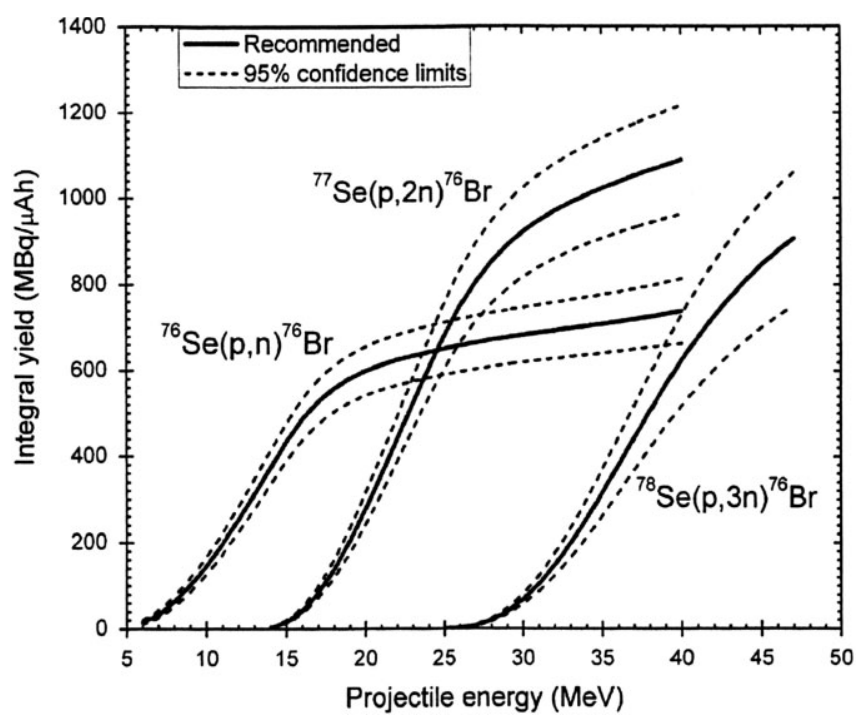

Fig. 3. Calculated integral yields for the ${ }^{76} \mathrm{Se}(p, n){ }^{76} \mathrm{Br},{ }^{77} \mathrm{Se}(p, 2 n){ }^{76} \mathrm{Br}$ and ${ }^{76} \mathrm{Se}(p, 3 n){ }^{76} \mathrm{Br}$ reactions (after Ref. [63]).
${ }^{73} \mathrm{Se}\left(T_{1 / 2}=7.1 \mathrm{~h}\right),{ }^{76} \mathrm{Br}\left(T_{1 / 2}=16.2 \mathrm{~h}\right),{ }^{89} \mathrm{Zr}\left(T_{1 / 2}=78.4 \mathrm{~h}\right)$, etc. Detailed reports on formation cross sections of several novel positron emitters via low and intermediate energy reactions have been published in recent years [cf. 57-62]. As an example, we consider the data for the production of ${ }^{76} \mathrm{Br}[59,60]$. An evaluation has been done [63] and from the recommended cross sections the yields of ${ }^{76} \mathrm{Br}$ via three reactions, namely ${ }^{76} \mathrm{Se}(p, n){ }^{76} \mathrm{Br},{ }^{77} \mathrm{Br}(p, 2 n)^{76} \mathrm{Br}$ and ${ }^{78} \mathrm{Se}(p, 3 n){ }^{76} \mathrm{Br}$, were calculated. The results are reproduced in Fig. 3. The method for production of this radionuclide could thus be chosen according to the proton energy available at the cyclotron. In practice, however, the ${ }^{76} \mathrm{Se}(p, n){ }^{76} \mathrm{Br}$ reaction is preferred because of the lowest level of the ${ }^{77} \mathrm{Br}\left(T_{1 / 2}=56.0 \mathrm{~h}\right)$ impurity.

Measurements have also been reported on parent radionuclides of some potentially useful positron emitting generator radionuclides (e.g. ${ }^{44} \mathrm{Ti}(60.4 \mathrm{a}) /{ }^{44} \mathrm{Sc}(3.9 \mathrm{~h})$ ); ${ }^{62} \mathrm{Zn}(9.1 \mathrm{~h}) /{ }^{62} \mathrm{Cu}(9.7 \mathrm{~min})$, etc. $[64,65]$. Further extensive cross section data work on many radionuclides is continuing in several laboratories.

\subsection{Novel therapeutic radionuclides}

The new trend in internal radionuclide therapy is to make use of radionuclides emitting low-range but highly ionising radiation, i.e. low-energy alpha- and beta-particle emitters, $\mathrm{X}$-ray emitters or Auger electron emitters. The topic has been discussed in some detail in a recent article [7]. In the present contribution, therefore, only a few selected aspects are dealt with.

Among the $\beta^{-}$emitters, the radionuclides ${ }^{67} \mathrm{Cu}\left(T_{1 / 2}=\right.$ $\left.2.58 \mathrm{~d} ; E_{\beta^{-}}=577 \mathrm{keV}\right)$ and ${ }^{186} \operatorname{Re}\left(T_{1 / 2}=3.72 \mathrm{~d} ; E_{\beta^{-}}=\right.$ $1070 \mathrm{keV}$ ) have been receiving enhanced attention. Radiochemical measurements [cf. 66] showed that a highly enriched ${ }^{68} \mathrm{Zn}$ target and the energy range $E_{\mathrm{p}}=70 \rightarrow$ $30 \mathrm{MeV}$ lead to ${ }^{67} \mathrm{Cu}$ of high quality. Two other new measurements on the reactions ${ }^{64} \mathrm{Ni}(\alpha, p){ }^{67} \mathrm{Cu}$ [67] and ${ }^{70} \mathrm{Zn}(d, \alpha n){ }^{67} \mathrm{Cu}$ [68] utilizing highly-enriched targets reveal that, similar to the ${ }^{70} \mathrm{Zn}(p, \alpha)^{67} \mathrm{Cu}$ process [44], large scale production of ${ }^{67} \mathrm{Cu}$ via the two new routes is also not feasible. The necessity of a $70 \mathrm{MeV}$ proton beam for the production of ${ }^{67} \mathrm{Cu}$ is thus imminent.

With regard to the production of ${ }^{186} \mathrm{Re}$, the suggested method is the ${ }^{186} \mathrm{~W}(p, n){ }^{186} \mathrm{Re}$ reaction, though the ${ }^{186} \mathrm{~W}(d, 2 n){ }^{186} \mathrm{Re}$ reaction has also been investigated and gives higher yield than the $(p, n)$ reaction. Several measurements for the ${ }^{186} \mathrm{~W}(p, n){ }^{186} \mathrm{Re}$ reaction have been reported in recent years [ $c f$. 69-74]. An analysis of those data was carried out $[9,75]$ and the result is given in Fig. 4. Calculations done using the three nuclear model codes, namely STAPRE, EMPIRE and TALYS, reproduce most of the data well [75]. From a critical discussion it was concluded [75] that for obtaining high-purity ${ }^{186} \mathrm{Re}$, an enriched ${ }^{186} \mathrm{~W}$ target is absolutely necessary and the maximum proton energy should not exceed $18 \mathrm{MeV}$.

Among the potentially useful X-ray and Auger electron emitters, the radionuclides ${ }^{131} \mathrm{Cs}\left(T_{1 / 2}=9.7 \mathrm{~d}\right.$; X-rays $)$, ${ }^{140} \mathrm{Nd}\left(T_{1 / 2}=3.37 \mathrm{~d}\right.$; Auger electrons $),{ }^{193 \mathrm{~m}} \mathrm{Pt}\left(T_{1 / 2}=4.33 \mathrm{~d}\right.$; Auger electrons) and ${ }^{195 \mathrm{~m}} \mathrm{Pt}\left(T_{1 / 2}=4.02 \mathrm{~d}\right.$; Auger electrons) have attracted some attention. The radionuclide ${ }^{131} \mathrm{Cs}$ is of considerable promise for prostate cancer brachytherapy. 


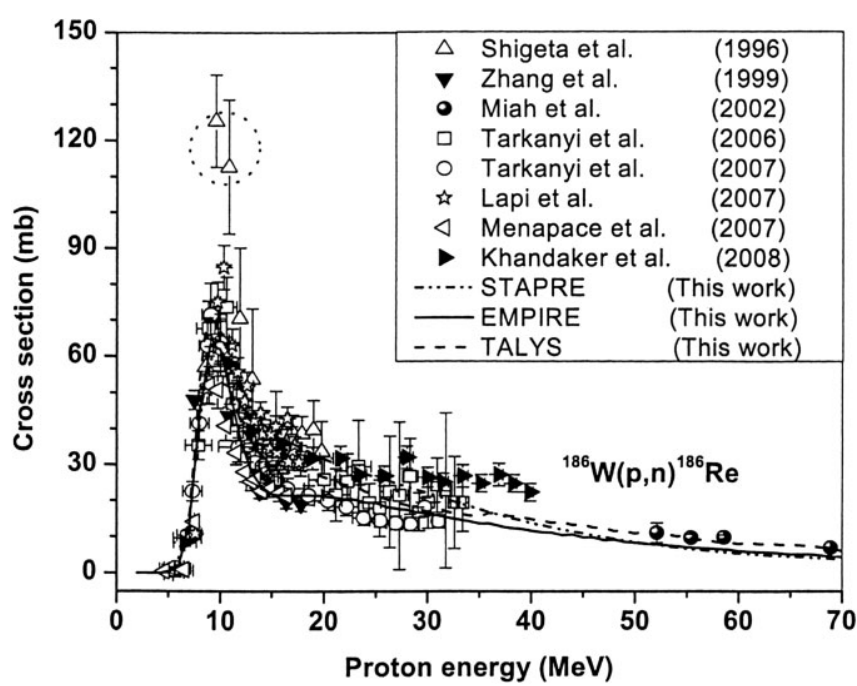

Fig. 4. Normalised experimental data and results of nuclear model calculations for the ${ }^{186} \mathrm{~W}(p, n){ }^{186} \mathrm{Re}$ reaction (after Ref. [75]).

Its effective production through the ${ }^{131} \mathrm{Xe}(p, n){ }^{131} \mathrm{Cs}$ reaction has been demonstrated [cf. 76]. The radionuclide ${ }^{140} \mathrm{Nd}$ is interesting, not only because of its therapeutic effect but also because of its positron-emitting short-lived daughter ${ }^{140} \operatorname{Pr}\left(T_{1 / 2}=3.4 \mathrm{~min}\right)$ which allows its localisation via PET imaging. Its production is carried out either by the ${ }^{n a t} \mathrm{Ce}\left({ }^{3} \mathrm{He}, x n\right){ }^{140} \mathrm{Nd}$ process or through the ${ }^{141} \operatorname{Pr}(p, 2 n){ }^{140} \mathrm{Nd}$ reaction $[c f .77,78]$. Cross section data for its production via the ${ }^{141} \operatorname{Pr}(d, 3 n)^{140} \mathrm{Nd}$ reaction have also been reported [79].

The radionuclides ${ }^{193 \mathrm{~m}} \mathrm{Pt}$ and ${ }^{195 \mathrm{~m}} \mathrm{Pt}$ are pure X-ray and Auger electron emitters, each decay leading to more than 30 secondary electrons. Thus both those radionuclides have great potential in Auger electron therapy. In a recent study it could be shown that small amounts of ${ }^{195 \mathrm{~m}} \mathrm{Pt}$ can be produced with high specific activity via the ${ }^{192} \mathrm{Os}(\alpha, \mathrm{n})^{195 \mathrm{~m}} \mathrm{Pt}$ reaction [80]. Using the same target but higher energy $\alpha$ particles, on the other hand, it was found that ${ }^{193 \mathrm{~m}} \mathrm{Pt}$ of high specific activity could be advantageously produced through the ${ }^{192} \mathrm{Os}(\alpha, 3 \mathrm{n}){ }^{193 \mathrm{~m}} \mathrm{Pt}$ reaction [81]. Over the optimum energy range $E_{\alpha}=40 \rightarrow 30 \mathrm{MeV}$, this radionuclide can be produced in quantities sufficient for therapeutic applications.

Regarding targeted $\alpha$-particle therapy, the radionuclide ${ }^{211}$ At $\left(T_{1 / 2}=7.2 \mathrm{~h} ; E_{\alpha}=5870 \mathrm{keV}\right)$ has been under investigation for quite some time. Its production data via the ${ }^{209} \mathrm{Bi}(\alpha, 2 \mathrm{n})^{211}$ At reaction are well known. Presently there is great demand for the radionuclide ${ }^{225} \mathrm{Ac}\left(T_{1 / 2}=10.0 \mathrm{~d} ; E_{\alpha}=\right.$ $5830 \mathrm{keV}$ ) which is useful in itself as well as for providing ${ }^{213} \mathrm{Bi}\left(T_{1 / 2}=46 \mathrm{~min} ; E_{\alpha}=5900 \mathrm{keV}\right)$ through a generator system. In recent years some interest has also developed in ${ }^{226} \mathrm{Th}\left(T_{1 / 2}=31 \mathrm{~min} ; E_{\alpha}=6340 \mathrm{keV}\right)$ and ${ }^{223} \mathrm{Ra}\left(T_{1 / 2}=\right.$ $\left.11.43 \mathrm{~d} ; E_{\alpha}=5720 \mathrm{keV}\right)$. Extensive effort is presently being invested in the development of ${ }^{225} \mathrm{Ac}$. On one hand its separation from nuclear waste $\left({ }^{229} \mathrm{Th}\right)$ is being optimised and, on the other, the ${ }^{226} \mathrm{Ra}(p, 2 n){ }^{225} \mathrm{Ac}$ reaction, making use of the radioactive target material ${ }^{226} \mathrm{Ra}$, is being developed [cf. 82]. A third possibility under investigation is its production via irradiation of ${ }^{232} \mathrm{Th}$ with intermediate energy protons [83-85]. The yield of ${ }^{225} \mathrm{Ac}$ and the level of the ${ }^{227} \mathrm{Ac}\left(T_{1 / 2}=21.8 \mathrm{a}\right)$ impurity calculated from the recently reported data [83] are given in Fig. 5. At a proton energy

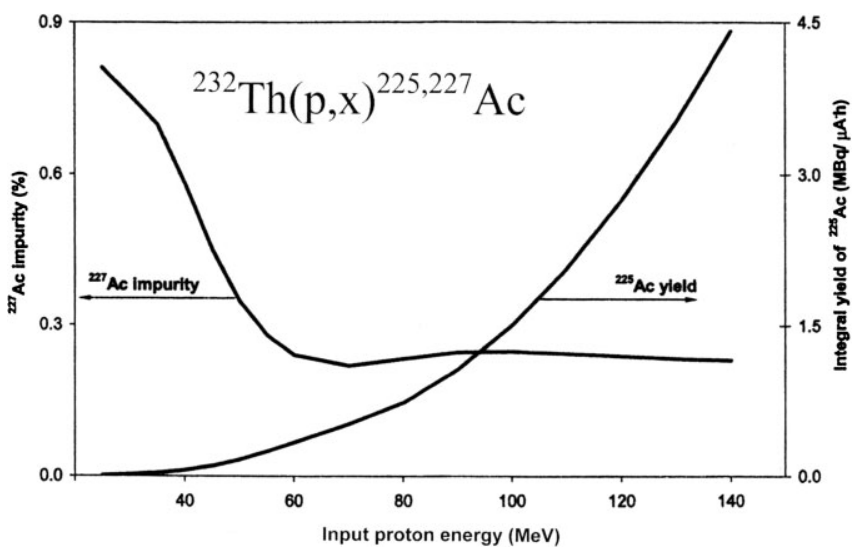

Fig. 5. Production yield of ${ }^{225} \mathrm{Ac}$ and level of ${ }^{227} \mathrm{Ac}$ impurity depending on inlet proton energy on a thick ${ }^{232} \mathrm{Th}$ target and outlet energy of $21 \mathrm{MeV}$ (after Ref. [83]).

of $140 \mathrm{MeV}$ the yield of ${ }^{225} \mathrm{Ac}$ amounts to $4.2 \mathrm{MBq} / \mu \mathrm{Ah}$ which is lower than the value of about $7 \mathrm{MBq} / \mu \mathrm{A} h$ via the ${ }^{226} \operatorname{Ra}(p, 2 n){ }^{225} \mathrm{Ac}$ reaction. The advantage of the new route is that the use of the radioactive target ${ }^{226} \mathrm{Ra}$ is avoided. The disadvantages are: lower yield, need of an intermediate energy accelerator and extensive effort in chemical processing. Anyway, both the latter two methods need considerable further development.

The $\alpha$-emitting radionuclide ${ }^{223} \mathrm{Ra}$ holds great promise for bone cancer therapy. It was obtained via the chain ${ }^{226} \operatorname{Ra}(n, \gamma){ }^{227} \mathrm{Ra} \quad(42.2 \mathrm{~min}) \stackrel{\beta^{-}}{\rightarrow}{ }^{227} \mathrm{Ac} \quad(21.8 \mathrm{a}) \stackrel{\beta^{-}}{\rightarrow}{ }^{227} \mathrm{Th}$ $(18.7 \mathrm{~d}) \stackrel{\alpha}{\rightarrow}{ }^{223} \mathrm{Ra}$. Another potentially interesting production route entails the irradiation of ${ }^{232} \mathrm{Th}$ with intermediate energy protons [cf. 83-85].

The production of ${ }^{230} \mathrm{U}$ (and its daughter ${ }^{226} \mathrm{Th}$ ) has been studied via ${ }^{231} \mathrm{~Pa}(p, 2 n)^{230} \mathrm{U},{ }^{231} \mathrm{~Pa}(d, 3 n)^{230} \mathrm{U}$ and ${ }^{232} \mathrm{Th}(p, 3 n)^{230} \mathrm{~Pa} \stackrel{\beta^{-}}{\rightarrow}{ }^{230} \mathrm{U}$ processes [86-88]. The target material ${ }^{231} \mathrm{~Pa}$ is radioactive; the chemical separation involved is thus very demanding [86].

\section{Conclusions}

Radionuclide production technology is well established and the relevant nuclear data for production of the commonly used radionuclides have been standardised. Yet some nuclear data activities are continuously underway to improve the quality of the products, i.e. either decrease the level of radioactive impurities or improve the specific activity of the product. In recent years, considerable effort has been devoted to searching for alternative routes for the production of ${ }^{99 \mathrm{~m}} \mathrm{Tc}$. The major thrust of the nuclear data research today is, however, towards developing non-conventional novel positron emitters and therapeutic radionuclides. The nonstandard metallic positron emitters are opening new perspectives in radioimmunotherapy and quantitative radiation dosimetry. The use of low-range but highly ionising radiation in targeted therapy is attracting great attention. It is anticipated that nuclear data work related to the development of the two types of radionuclides will continue also in the future. Newer medical applications, e.g. multimode imaging, combination of radioactivity with nanotechnology, etc., will demand novel radionuclides. For their production, applica- 
tion of intermediate energy cyclotrons, accelerating all four light charged particles, viz. p, d, ${ }^{3} \mathrm{He}$ and ${ }^{4} \mathrm{He}$, may be necessary. In particular, an intermediate energy $\alpha$-particle beam holds great promise for producing high-spin isomers which decay by Auger electron emission and are thus potentially very interesting for Auger therapy.

\section{References}

1. Stöcklin, G., Qaim, S. M., Rösch, F.: The impact of radioactivity on medicine. Radiochim. Acta 70/71, 249-272 (1995).

2. Qaim, S. M.: Nuclear data relevant to cyclotron-produced shortlived medical radionuclides. Radiochim. Acta 30, 147-162 (1982).

3. Qaim, S. M.: Nuclear data relevant to the production and application of diagnostic radionuclides. Radiochim. Acta 89, 223-232 (2001).

4. Qaim, S. M.: Therapeutic radionuclides and nuclear data. Radiochim. Acta 89, 297-302 (2001).

5. Qaim, S. M.: Recent advances in nuclear data research for medical applications. J. Korean Phys. Soc. 59, 1965-1970 (2011).

6. Qaim, S. M.: Development of novel positron emitters for medical applications: nuclear and radiochemical aspects. Radiochim. Acta 99, 611-625 (2011).

7. Qaim, S. M.: The present and future of medical radionuclide production. Radiochim. Acta 100, 635-651 (2012).

8. Gul, K., Hermanne, A., Mustafa, M. G., Nortier, F. M., Oblozinsky, P., Qaim, S. M., Scholten, B., Shubin, Yu., Takács, S., Tárkányi, F. T., Zhuang, Y.: Charged particle cross section database for medical radioisotope production: diagnostic radioisotopes and monitor reactions. IAEA-TECDOC-1299 (2008), pp. 1-285.

9. Qaim, S. M., Tárkányi, F., Capote, R. (Eds): Nuclear data for the production of therapeutic radionuclides. IAEA Tech. Rep. Ser. No. 473, 1-358 (2011)

10. Tárkányi, F., Takács, S., Király, B., Szelecsényi, F., Andó, L., Bergman, J., Heselius, S. J., Hermanne, A., Shubin, Yu. N., Ignatyuk, A. V.: Excitation functions of ${ }^{3} \mathrm{He}$ - and $\alpha$-particle induced nuclear reactions on ${ }^{\text {nat }} \mathrm{Sb}$ for production of medically relevant ${ }^{123} \mathrm{I}$ and ${ }^{124}$ I radioisotopes. Appl. Radiat. Isot. 67, 1001-1006 (2009).

11. Hussain, M., Sudár, S., Aslam, N. M., Shah, H. A., Malik, A. A., Qaim, S. M.: A comprehensive evaluation of charged-particle data for production of the therapeutic radionuclide ${ }^{103} \mathrm{Pd}$. Appl. Radiat. Isot. 67, 1842-1854 (2009).

12. Kovács, Z., Scholten, B., Tárkányi, F., Coenen, H. H., Qaim, S. M. Cross section measurements using gas and solid targets for production of the positron emitting radionuclide ${ }^{14} \mathrm{O}$. Radiochim. Acta 91, 185-189 (2003).

13. Hess, E., Takács, S., Scholten, B., Tárkányi, F., Coenen, H. H., Qaim, S. M.: Excitation function of the ${ }^{18} \mathrm{O}(p, n)^{18} \mathrm{~F}$ nuclear reaction from threshold up to $30 \mathrm{MeV}$. Radiochim. Acta 89, 357-362 (2001).

14. Kettern, K., Shubin, Yu. N., Steyn, G. F., van der Walt, T. N., Coenen, H. H., Qaim, S. M.: Formation of short-lived positron emitters in reactions of protons of energies up to $200 \mathrm{MeV}$ with the target elements carbon, nitrogen and oxygen. Appl. Radiat. Isot. 60, 939-945 (2004).

15. Qaim, S. M., Steyn, G. F., Spahn, I., Spellerberg, S., van der Walt, T. N., Coenen, H. H.: Yield and purity of ${ }^{82} \mathrm{Sr}$ produced via the ${ }^{\text {nat }} \mathrm{Rb}(p, x n)^{82} \mathrm{Sr}$ process. Appl. Radiat. Isot. 65, 247-252 (2007).

16. Adam-Rebeles, R., Hermanne, A., van den Winkel, P., De Vis, L., Waegeneer, R., Tárkányi, F., Takács, S., Takács, M. P.: ${ }^{66} \mathrm{Ge} /{ }^{68} \mathrm{Ga}$ production revisited: new excitation curves, target preparation and chemical separation-purification. Radiochim. Acta 101, DOI: 10.1524/ract.2013.2057 (2013).

17. Hermanne, A., Tárkányi, F., Takács, S., Adam-Rebeles, R., Ignatyuk, A., Spellerberg, S., Schweickert, H.: Limitation of the long-lived ${ }^{121} \mathrm{Te}$ contaminant in production of ${ }^{123} \mathrm{I}$ through the ${ }^{124} \mathrm{Xe}(p, x)$ route. Appl. Radiat. Isot. 69, 358-368 (2011).

18. Al-Abyad, M., Comsan, M. N. H., Qaim, S. M.: Excitation functions of proton-induced reactions on ${ }^{\text {nat }} \mathrm{Fe}$ and enriched ${ }^{57} \mathrm{Fe}$ with particular reference to production of ${ }^{57} \mathrm{Co}$. Appl. Radiat. Isot. 67, 122-128 (2009).

19. Spahn, I., Coenen, H. H., Qaim, S. M.: Enhanced production possibility of the therapeutic radionuclides ${ }^{64} \mathrm{Cu},{ }^{67} \mathrm{Cu}$ and ${ }^{89} \mathrm{Sr}$ via $(n, p)$ reactions induced by fast spectral neutrons. Radiochim. Acta 92, 183-186 (2004).

20. Al-Abyad, M., Spahn, I., Sudár, S., Morsy, M., Comsan, M. N. H., Csikai, J., Qaim, S. M., Coenen, H. H.: Nuclear data for production of the therapeutic radionuclides ${ }^{32} \mathrm{P},{ }^{64} \mathrm{Cu},{ }^{67} \mathrm{Cu},{ }^{89} \mathrm{Sr},{ }^{90} \mathrm{Y}$ and ${ }^{153} \mathrm{Sm}$ via the $(n, p)$ reaction: Evaluation of excitation function and its validation via integral cross section measurement using a $14 \mathrm{MeV}$ d(Be) neutron source. Appl. Radiat. Isot. 64, 717-724 (2006).

21. Zaidi, J. H., Arif, M., Fatima, I., Waheed, S., Ahmad, S., Qureshi, I. H.: Fission-spectrum averaged cross section measurements of some neutron threshold reactions of relevance to medical radioisotope production. Radiochim. Acta 93, 547-552 (2005).

22. Rajput, M. U., Maidana, N. L., Vanin, V. R., Dias, M. S., Koskinas, M. F.: Measurement of thermal neutron cross section and resonance integral for the ${ }^{165} \mathrm{Ho}(n, \gamma){ }^{166 g} \mathrm{Ho}$ reaction. Radiochim. Acta 97, 63-69 (2009).

23. Aslam, M. N., Sudár, S., Hussain, M., Malik, A. A., Shah, H. A., Qaim, S. M.: Charged particle induced reaction cross section data for production of the emerging medically important positron emitter ${ }^{64} \mathrm{Cu}$ : A comprehensive evaluation. Radiochim. Acta 97, 669686 (2009).

24. Hilgers, K., Sudár, S., Qaim, S. M.: Experimental study and nuclear model calculations on the ${ }^{192} \mathrm{Os}(p, n)^{192} \mathrm{Ir}$ reaction: comparison of reactor and cyclotron production of the therapeutic radionuclide ${ }^{192}$ Ir. Appl. Radiat. Isot. 63, 93-98 (2005).

25. Spahn, I., Takács, S., Shubin, Yu.N., Tárkányi, F., Coenen, H. H., Qaim, S. M.: Cross section measurement of the ${ }^{169} \mathrm{Tm}(p, n)$ reaction for the production of the therapeutic radionuclide ${ }^{169} \mathrm{Yb}$ and comparison with its reactor based generation. Appl. Radiat. Isot. 63, 235-239 (2005).

26. Tárkányi, F., Hermanne, A., Takács, S., Hilgers, K., Kovalev, S. F., Ignatyuk, A. V., Qaim, S. M.: Study of the ${ }^{192} \mathrm{Os}(d, 2 n)$-reaction for production of the therapeutic radionuclide ${ }^{192} \mathrm{Ir}$ in no-carrieradded form. Appl. Radiat. Isot. 65, 1215-1220 (2007).

27. Király, B., Tárkányi, F., Takács, S., Hermanne, A., Kovalev, S. F., Ignatyuk, A. V.: Excitation functions of alpha-induced nuclear reactions on natural erbium. Nucl. Instrum. Methods B 266, 549554 (2008).

28. Tárkányi, F., Hermanne, A., Takács, S., Ditrói, F., Király, B., Kovalev, S. F., Ignatyuk, A. V.: Experimental study of the ${ }^{165} \mathrm{Ho}(p, n)$ nuclear reaction for production of the therapeutic radioisotope ${ }^{165}$ Er. Nucl. Instrum. Methods B 266, 3346-3352 (2008).

29. Tárkányi, F., Hermanne, A., Takács, S., Ditrói, F., Király, B., Kovalev, S. F., Ignatyuk, A. V.: Experimental study of the ${ }^{165} \mathrm{Ho}(d, 2 n)$ and ${ }^{165} \mathrm{Ho}(d, p)$ nuclear reactions up to $20 \mathrm{MeV}$ for production of the therapeutic radioisotopes ${ }^{165} \mathrm{Er}$ and ${ }^{166 \mathrm{H}} \mathrm{Ho}$. Nucl. Instrum. Methods B 266, 3529-3534 (2008).

30. Tárkányi, F., Takács, S., Hermanne, A., Ditrói, F., Király, B., Baba, M., Ohtsuki, T.: Investigation of production of the therapeutic radioisotope ${ }^{165} \mathrm{Er}$ by proton induced reactions on erbium in comparison with other production routes. Appl. Radiat. Isot. 67, 243-247 (2009)

31. Qaim, S. M., Spahn, I., Kandil, S. A., Coenen, H. H.: Nuclear data for production of ${ }^{88} \mathrm{Y},{ }^{140} \mathrm{Nd},{ }^{153} \mathrm{Sm}$ and ${ }^{169} \mathrm{Yb}$ via novel routes. Radiochim. Acta 95, 313-317 (2007).

32. Scholten, B., Lambrecht, R. M., Cogneau, M., Vera Ruiz, H., Qaim, S. M.: Excitation functions for the cyclotron production of ${ }^{99 \mathrm{~m}} \mathrm{Tc}$ and ${ }^{99} \mathrm{Mo}$. Appl. Radiat. Isot. 51, 69-80 (1999).

33. Lebeda, O., Pruszynski, M.: New measurements of excitation functions for $(p, x)$ reactions on ${ }^{\text {nat }}$ Mo with special regard to the formation of ${ }^{95 \mathrm{~m}} \mathrm{Tc},{ }^{99 \mathrm{~m}} \mathrm{Tc}$ and ${ }^{99} \mathrm{Mo}$. Appl. Radiat. Isot. 68, 23552365 (2010).

34. Gagnon, K., Bénard, F., Kovacs, M., Ruth, T. J., Schaffer, P., Wilson, J. S., McQuarrie, S. A.: Cyclotron production of ${ }^{99 \mathrm{~m}} \mathrm{Tc}$ : Experimental measurement of the ${ }^{100} \mathrm{Mo}(p, x){ }^{99} \mathrm{Mo},{ }^{99 \mathrm{~m}} \mathrm{Tc}$ and ${ }^{99 \mathrm{~g}} \mathrm{Tc}$ excitation functions from 8 to $18 \mathrm{MeV}$. Nucl. Med. Biol. 38, 907916 (2011).

35. Khandaker, M. U., Meaze, A. K. M. M.H., Kim, K., Son, G. D., Kim, G.: Measurements of the proton-induced reaction cross sec- 
tions of ${ }^{\text {nat }}$ Mo by using the MC50 cyclotron at the Korea Institute of Radiological and Medical Sciences. J. Korean Phys. Soc. 48, 821-826 (2006).

36. Tárkányi, F., Ditrói, F., Hermanne, A., Takács, S., Ignatyuk, A. V.: Investigation of activation cross sections of proton-induced nuclear reactions on ${ }^{\text {nat }} \mathrm{Mo}$ up to $40 \mathrm{MeV}$ : new data and evaluation. Nucl. Instrum. Methods B 280, 45-73 (2012).

37. Qaim, S. M., Sudár, S., Scholten, B., Koning, A. J., Coenen, H. H.: Evaluation of excitation functions of ${ }^{100} \mathrm{Mo}(p, d+p n)^{99} \mathrm{Mo}$ and ${ }^{100} \mathrm{Mo}(p, 2 n){ }^{99 \mathrm{~m}} \mathrm{Tc}$ reactions: estimation of long-lived Tc-impurity and its implication on the specific activity of cyclotron-produced ${ }^{99 m}$ Tc. Appl. Radiat. Isot., submitted.

38. Szelecsényi, F., Kovács, Z., Nagatsu, K., Fukumura, K., Suzuki, K., Mukai, K.: Investigations of direct production of ${ }^{68} \mathrm{Ga}$ with low energy multiparticle accelerator. Radiochim. Acta 100, 5-11 (2012).

39. Qaim, S. M.: Decay data and production yields of some nonstandard positron emitters used in positron emission tomography. Quarterly, J. Nucl. Med. Mol. Imaging 52, 111-120 (2008).

40. Szelecsényi, F., Blessing, G., Qaim, S. M.: Excitation functions of proton induced nuclear reactions on enriched ${ }^{61} \mathrm{Ni}$ and ${ }^{64} \mathrm{Ni}$ : possibility of production of no-carrier-added ${ }^{61} \mathrm{Cu}$ and ${ }^{64} \mathrm{Cu}$ at a small cyclotron. Appl. Radiat. Isot. 44, 575-580 (1993).

41. Rösch, F., Qaim, S. M., Stöcklin, G.: Nuclear data relevant to the production of the positron emitting radioisotope ${ }^{86} \mathrm{Y}$ via the ${ }^{86} \mathrm{Sr}(p, n)$ - and ${ }^{\text {nat }} \mathrm{Rb}\left({ }^{3} \mathrm{He}, x n\right)$-processes. Radiochim. Acta 61, 18 (1993).

42. Scholten, B., Kovács, Z., Tárkányi, F., Qaim, S. M.: Excitation functions of ${ }^{124} \mathrm{Te}(p, x n)^{124,123} \mathrm{I}$ reactions from 6 to $31 \mathrm{MeV}$ with special reference to the production of ${ }^{124} \mathrm{I}$ at a small cyclotron. Appl. Radiat. Isot. 46, 255-259 (1995).

43. Rebeles, R. A., van den Winkel, P., Hermanne, A., Tárkányi, F. New measurements and evaluation of the excitation function of ${ }^{64} \mathrm{Ni}(p, n)$-reaction for the production of ${ }^{64} \mathrm{Cu}$. Nucl. Instrum. Methods B 267, 457-461 (2009).

44. Hilgers, K., Stoll, T., Skakun, Y., Coenen, H. H., Qaim, S. M.: Cross section measurements of the nuclear reactions ${ }^{n a t} \mathrm{Zn}(d, x){ }^{64} \mathrm{Cu},{ }^{66} \mathrm{Zn}(d, \alpha){ }^{64} \mathrm{Cu}$ and $\left.{ }^{68} \mathrm{Zn}(p, \alpha n)\right)^{64} \mathrm{Cu}$ for production of ${ }^{64} \mathrm{Cu}$ and technical developments for small scale production of ${ }^{67} \mathrm{Cu}$ via the ${ }^{70} \mathrm{Zn}(p, \alpha){ }^{67} \mathrm{Cu}$ process. Appl. Radiat. Isot. 59, 343-351 (2003).

45. Szeleczényi, F., Steyn, G. F., Kovács, Z., Vermeulen, C., van der Meulen, N. P., Dolley, S. G., van der Walt, T. N., Suzuki, K., Mukai, K.: Investigation of the ${ }^{66} \mathrm{Zn}(p, 2 p n){ }^{64} \mathrm{Cu}$ and ${ }^{68} \mathrm{Zn}(p, x)$ ${ }^{64} \mathrm{Cu}$ nuclear processes up to $100 \mathrm{MeV}$ : production of ${ }^{64} \mathrm{Cu}$. Nucl. Instrum. Methods B 240, 625-637 (2005).

46. Tárkányi, F., Takács, S., Ditrói, F., Hermanne, A., Sonck, M., Shubin, Yu.: Excitation functions of deuteron induced nuclear reactions on natural zinc up to $50 \mathrm{MeV}$. Nucl. Instrum. Methods B 217, 531-550 (2004).

47. Groppi, F., Bonardi, M. L., Birattari, C., Gini, L., Mainardi, C., Menapace, E., Abbas, K., Holzwarth, U., Stroosnijder, R. M. F. Thin target excitation functions and optimization of ${ }^{N C A}{ }^{64} \mathrm{Cu}$ and ${ }^{66,67} \mathrm{Ga}$ production by deuteron induced nuclear reactions on natural zinc target for radiometabolic therapy and for PET. Nucl. Instrum. Methods B 213, 373-377 (2004).

48. Abbas, K., Kozempel, J., Bonardi, M., Groppi, F., Alfarano, A., Holzwarth, U., Simonelli, F., Hofmann, H., Horstmann, W., Menapace, E., Lešetický, L., Gibson, N.: Cyclotron production of ${ }^{64} \mathrm{Cu}$ by deuteron irradiation of ${ }^{64} \mathrm{Zn}$. Appl. Radiat. Isot. 64, 1001-1005 (2006).

49. Kozempel, J., Abbas, K., Simonelli, F., Zampese, M., Holzwarth, U., Gibson, N., Lešetický, L.: A novel method for n.c.a. ${ }^{64} \mathrm{Cu}$ production by the ${ }^{64} \mathrm{Zn}(d, 2 p){ }^{64} \mathrm{Cu}$ reaction and dual ion-exchange column chromatography. Radiochim. Acta 95, 75-80 (2007).

50. Medvedev, D. G., Mausner, L. F., Srivastava, S.: Irradiation of strontium chloride targets at proton energies above $35 \mathrm{MeV}$ to produce PET radioisotope ${ }^{86} \mathrm{Y}$. Radiochim. Acta 99, 755-761 (2011).

51. Hohn, A., Nortier, F. M., Scholten, B., van der Walt, T. N., Coenen, H. H., Qaim, S. M.: Excitation functions of ${ }^{125} \mathrm{Te}(p, x n)$ reactions from their thresholds up to $100 \mathrm{MeV}$ with special reference to the production of ${ }^{124}$ I. Appl. Radiat. Isot. 55, 149-156 (2001).
52. Hassan, K. F., Qaim, S. M., Saleh, Z. A., Coenen, H. H.: Alphaparticle induced reactions on ${ }^{\text {nat }} \mathrm{Sb}$ and ${ }^{121} \mathrm{Sb}$ with particular reference to the production of the medically interesting radionuclide ${ }^{124}$ I. Appl. Radiat. Isot. 64, 101-109 (2006).

53. Hassan, K. F., Qaim, S. M., Saleh, Z. A., Coenen, H. H.: ${ }^{3} \mathrm{He}-$ particle induced reactions on ${ }^{\text {nat }} \mathrm{Sb}$ for production of ${ }^{124} \mathrm{I}$. Appl. Radiat. Isot. 64, 409-413 (2006).

54. Uddin, M. S., Hermanne, A., Sudár, S., Aslam, M. N., Scholten, B., Coenen, H. H., Qaim, S. M.: Excitation functions of $\alpha$-particle induced reactions on enriched ${ }^{123} \mathrm{Sb}$ and ${ }^{\text {nat }} \mathrm{Sb}$ for production of ${ }^{124} \mathrm{I}$. Appl. Radiat. Isot. 69, 699-704 (2011).

55. Aslam, M. N., Sudár, S., Hussain, M., Malik, A. A., Shah, H. A., Qaim, S. M.: Evaluation of excitation functions of proton and deuteron induced reactions on enriched tellurium isotopes with special relevance to the production of iodine-124. Appl. Radiat. Isot. 68, 1760-1773 (2010).

56. Aslam, M. N., Sudár, S., Hussain, M., Malik, A. A., Qaim, S. M.: Evaluation of excitation functions of ${ }^{3} \mathrm{He}$ - and $\alpha$-particle induced reactions on antimony isotopes with special relevance to the production of iodine-124. Appl. Radiat. Isot. 69, 94-104 (2011).

57. Spahn, I., Steyn, G., Nortier, F. M., Coenen, H. H., Qaim, S. M.: Excitation functions of ${ }^{\text {nat }} \mathrm{Ge}(p, x n)^{71,72,73,74}$ As reactions up to $100 \mathrm{MeV}$ with a focus on the production of ${ }^{72} \mathrm{As}$ for medical and ${ }^{73}$ As for environmental studies. Appl. Radiat. Isot. 65, 1057-1064 (2007).

58. Scholten, B., Takács, S., Tárkányi, F., Coenen, H. H., Qaim, S. M.: Excitation functions of deuteron induced nuclear reactions on enriched ${ }^{78} \mathrm{Kr}$ with particular relevance to the production of ${ }^{76} \mathrm{Br}$. Radiochim. Acta 92, 203-207 (2004).

59. Hassan, H. E., Qaim, S. M., Shubin, Yu., Azzam, A., Morsy, M., Coenen, H. H.: Experimental studies and nuclear model calculations on proton induced reactions on ${ }^{\text {nat }} \mathrm{Se},{ }^{76} \mathrm{Se}$ and ${ }^{77} \mathrm{Se}$ with particular reference to the production of the medically interesting radionuclides ${ }^{76} \mathrm{Br}$ and ${ }^{77} \mathrm{Br}$. Appl. Radiat. Isot. 60, 899-909 (2004).

60. Spahn, I., Steyn, G. F., Vermeulen, C., Kovács, Z., Szelecsényi, F., Coenen, H. H., Qaim, S. M.: New cross section measurements for production of the positron emitters ${ }^{75} \mathrm{Br}$ and ${ }^{76} \mathrm{Br}$ via intermediate energy proton induced reactions. Radiochim. Acta 97, 535-541 (2009).

61. Kandil, S. A., Spahn, I., Scholten, B., Saleh, Z. A., Saad, S. M. M., Coenen, H. H., Qaim, S. M.: Excitation functions of $(\alpha, x n)$ reactions on ${ }^{\text {nat }} \mathrm{Rb}$ and ${ }^{\text {nat }} \mathrm{Sr}$ from threshold up to $26 \mathrm{MeV}$ : possibility of production of ${ }^{87} \mathrm{Y},{ }^{88} \mathrm{Y}$ and ${ }^{89} \mathrm{Zr}$. Appl. Radiat. Isot. 65, 561568 (2007)

62. Busse, S., Rösch, F., Qaim, S. M.: Cross section data for the production of the positron emitting niobium isotope ${ }^{90} \mathrm{Nb}$ via the ${ }^{90} \mathrm{Zr}(p, n)$-reaction. Radiochim. Acta 90, 1-5 (2002).

63. Aslam, M. N., Sudár, S., Hussain, M., Malik, A. A., Qaim, S. M.: Evaluation of excitation functions of proton, ${ }^{3} \mathrm{He}$ - and $\alpha$-particle induced reactions for production of the medically interesting positron-emitter bromine-76. Appl. Radiat. Isot. 69, 1490-1505 (2011).

64. Daraban, L., Rebeles, R. A., Hermanne, A., Tárkányi, F., Takács, S.: Study of the excitation functions for ${ }^{43} \mathrm{~K},{ }^{43,44,44 \mathrm{~m}} \mathrm{Sc}$ and ${ }^{44} \mathrm{Ti}$ by proton irradiations of ${ }^{45} \mathrm{Sc}$ up to $37 \mathrm{MeV}$. Nucl. Instrum. Methods B 267, 755-759 (2009).

65. Szelecsényi, F., Kovács, Z., van der Walt, T. N., Steyn, G. F., Suzuki, K., Okada, K.: Investigation of the ${ }^{\text {nat }} \mathrm{Zn}(p, x)^{62} \mathrm{Zn}$ nuclear process up to $70 \mathrm{MeV}$ : a new ${ }^{62} \mathrm{Zn} /{ }^{62} \mathrm{Cu}$ generator. Appl. Radiat. Isot. 58, 377-384 (2003).

66. Stoll, T., Kastleiner, S., Shubin, Yu.N., Coenen, H. H., Qaim, S. M.: Excitation functions of proton induced reactions on ${ }^{68} \mathrm{Zn}$ from threshold up to $71 \mathrm{MeV}$, with specific reference to the production of ${ }^{67} \mathrm{Cu}$. Radiochim. Acta 90, 309-313 (2002).

67. Skakun, Ye., Qaim, S. M.: Excitation function of the ${ }^{64} \mathrm{Ni}(\alpha, p){ }^{67} \mathrm{Cu}$ reaction for production of ${ }^{67} \mathrm{Cu}$. Appl. Radiat. Isot. 60, 33-39 (2004).

68. Kozempel, J., Abbas, K., Simonelli, F., Bulgheroni, A., Holzwarth, U., Gibson, N.: Preparation of ${ }^{67} \mathrm{Cu}$ via deuteron irradiation of ${ }^{70} \mathrm{Zn}$. Radiochim. Acta 100, 419-423 (2012).

69. Miah, M. H., Kuhnhenn, J., Herpers, U., Michel, R., Kubik, P.: Production of residual nuclides by proton induced reactions on 
target $\mathrm{W}$ at an energy of $72 \mathrm{MeV}$. J. Nucl. Sci. Tech. Suppl. 2, 369-372 (2002).

70. Menapace, E., Birattari, C., Bonardi, M. L., Groppi, F.: Experimental results and model calculations of excitation functions relevant to the production of specific radioisotopes for metabolic radiotherapy and for PET. Radiat. Phys. Chem. 71, 943-945 (2004).

71. Tárkányi, F., Takács, S., Szelecsényi, F., Ditrói, F., Hermanne, A., Sonck, M.: Excitation functions of proton induced nuclear reactions on natural tungsten up to $34 \mathrm{MeV}$. Nucl. Instrum. Methods Phys. Res. B 252, 160-174 (2006).

72. Tárkányi, F., Hermanne, A., Takács, F., Ditrói, F., Kovalev, F., Ignatyuk, A. V.: New measurements and evaluation of excitation function of the ${ }^{186} \mathrm{~W}(p, n)$ nuclear reaction for production of the therapeutic radioisotope ${ }^{186} \mathrm{Re}$. Nucl. Instrum. Methods Phys. Res. B 264, 389-394 (2007).

73. Lapi, S., Mills, W. J., Wilson, J., McQuarrie, S., Publicover, J., Schueller, M., Schlyer, D., Ressler, J. J., Ruth, T. J.: Production cross sections of ${ }^{181-186} \mathrm{Re}$ isotopes from proton bombardment of natural tungsten. Appl. Radiat. Isot. 65, 345-349 (2007).

74. Khandaker, M. U., Uddin, M. S., Kim, K., Lee, M. W., Kim, K. S., Lee, Y. S., Kim, G. N., Cho, Y. S., Lee, Y. O.: Excitation functions of proton induced nuclear reactions on ${ }^{\text {nat }} \mathrm{W}$ up to $40 \mathrm{MeV}$. Nucl. Instrum. Methods Phys. Res. B 266, 1021-1029 (2008).

75. Hussain, M., Sudár, S., Aslam, M. N., Malik, A. A., Ahmad, R., Qaim, S. M.: Evaluation of charged particle induced reaction cross section data for production of the important therapeutic radionuclide ${ }^{186}$ Re. Radiochim. Acta 98, 385-395 (2010).

76. Tárkányi, F., Hermanne, A., Takács, S., Rebeles, R. A., van den Winkel, P., Király, B., Ditrói, F., Ignatyuk, A. V.: Cross section measurements of the ${ }^{131} \mathrm{Xe}(p, n)$ reaction for production of the therapeutic radionuclide ${ }^{131} \mathrm{Cs}$. Appl. Radiat. Isot. 67, 1751-1757 (2009).

77. Hilgers, K., Shubin, Yu.N., Coenen, H. H., Qaim, S. M.: Experimental measurements and nuclear model calculations on the excitation functions of nat $\mathrm{Ce}\left({ }^{3} \mathrm{He}, x n\right)$ and ${ }^{141} \operatorname{Pr}(p, x n)$ reactions with special reference to production of the therapeutic radionuclide ${ }^{140} \mathrm{Nd}$. Radiochim. Acta 93, 553-560 (2005).

78. Steyn, G. F., Vermeulen, C., Nortier, F. M., Szelecsényi, F., Kovács, Z., Qaim, S. M.: Production of no-carrier-added ${ }^{139} \mathrm{Pr}$ via

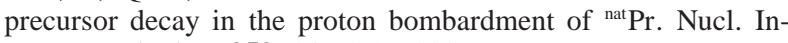
strum. Methods B 252, 149-159 (2006).

79. Herrmanne, A., Tárkányi, F., Takács, S., Ditrói, F., Baba, M., Ohtshuki, T., Spahn, I., Ignatyuk, A. V.: Excitation functions of pro- duction of medically relevant radioisotopes in deuteron irradiations of Pr and Tm targets. Nucl. Instrum. Methods B 267, 727-736 (2009).

80. Hilgers, K., Coenen, H. H., Qaim, S. M.: Production of the therapeutic radionuclides ${ }^{193 \mathrm{~m}} \mathrm{Pt}$ and ${ }^{195 \mathrm{~m}} \mathrm{Pt}$ with high specific activity via $\alpha$-particle induced reactions on ${ }^{192} \mathrm{Os}$. Appl. Radiat. Isot. 66, $545-551$ (2008)

81. Uddin, M. S., Scholten, B., Hermanne, A., Sudár, S., Coenen, H. H., Qaim, S. M.: Radiochemical determination of cross sections of $\alpha$-particle induced reactions on ${ }^{192} \mathrm{Os}$ for the production of the therapeutic radionuclide ${ }^{193 \mathrm{~m}} \mathrm{Pt}$. Appl. Radiat. Isot. 68, 2001-2006 (2010).

82. Apostolidis, C., Molinet, R., McGinley, J., Abbas, K., Möllenbeck, J., Morgenstern, A.: Cyclotron production of ${ }^{225} \mathrm{Ac}$ for targeted alpha therapy. Appl. Radiat. Isot. 62, 383-387 (2005).

83. Ermolaev, S. V., Zhuikov, B. L., Kokhanyuk, V. M., Matushko, V. L., Kalmykov, S. N., Aliev, R. A., Tananaev, I. G., Myasoedov, B. F.: Production of actinium, thorium and radium isotopes from natural thorium irradiated with protons up to $141 \mathrm{MeV}$. Radiochim. Acta 100, 223-229 (2012).

84. Weidner, J. W., Mashnik, S. G., John, K. D., Ballard, B., Birnbaum, E. R., Bitteker, L. J., Couture, A., Fassbender, M. E., Goff, G. S., Gritzo, R., Hemez, F. M., Runde, W., Ullmann, J. L., Wolfsberg, L. E., Nortier, F. M.: ${ }^{225} \mathrm{Ac}$ and ${ }^{223} \mathrm{Ra}$ production via $800 \mathrm{MeV}$ proton irradiation of natural thorium targets. Appl. Radiat. Isot. 70, 2590-2595 (2012).

85. Weidner, J. W., Mashnik, S. G., John, K. D., Hemez, F., Ballard, B., Bach, H., Birnbaum, E. R., Bitteker, L. J., Couture, A., Dry, D., Fassbender, M. E., Gulley, M. S., Jackman, K. R., Ullmann, J. L., Wolfsberg, L. E.: Proton-induced cross sections relevant to production of ${ }^{225} \mathrm{Ac}$ and ${ }^{226} \mathrm{Ra}$ in natural thorium targets below $200 \mathrm{MeV}$. Appl. Radiat. Isot. 70, 2602-2607 (2012).

86. Morgenstern, A., Lebeda, O., Stursa, J., Bruchertseifer, F., Capote, R., McGinley, J., Rasmussen, G., Sin, M., Zielinska, B., Apostolidis, C.: Production of U/Th for targeted therapy via proton irradiation of Pa. Anal. Chem. 80, 8763-8770 (2008).

87. Morgenstern, A., Lebeda, O., Stursa, J., Capote, R., Sin, M., Bruchertseifer, F., Zielinska, B., Apostolidis, C.: Cross sections of the reaction ${ }^{231} \mathrm{~Pa}(d, 3 n)^{230} \mathrm{U}$ for the production of ${ }^{230} \mathrm{U} /{ }^{226} \mathrm{Th}$ for targeted $\alpha$ therapy. Phys. Rev. C 80, 054612 (2009).

88. Morgenstern, A., Apostolidis, C., Bruchertseifer, F., Capote, R., Gouder, T., Simonelli, F., Sin, M., Abbas, K.: Cross sections of the reaction ${ }^{232} \mathrm{Th}(p, 3 n){ }^{230} \mathrm{~Pa}$ for production of ${ }^{230} \mathrm{U}$ for targeted alpha therapy. Appl. Radiat. Isot. 66, 1275-1280 (2008). 